\section{Task Analysis}

Amy J. Armstrong

Department of Rehabilitation Counseling, Virginia Commonwealth University, Richmond, VA, USA

\section{Definition}

It is an instructional strategy in which a task is analyzed, step by step, from the beginning to the completion of the respective task. The purpose of a task analysis is to determine the instructional goals and objectives, define and describe in detail the tasks and subtasks that the individual will perform, specify the knowledge type (declarative, structural, and procedural knowledge) that characterize a job or task, select learning outcomes that are appropriate for instructional development, prioritize and sequence tasks, determine instructional activities and strategies that foster learning, select appropriate media and learning environments, and construct performance assessments and evaluation (Jonassen et al. 1999).

Specific tasks to be analyzed are typically identified within the job analysis process and are often the core routines and/or essential functions of a respective job. Task analyses are used to assist individuals with cognitive and/or learning challenges to acquire the behaviors/skills necessary to perform a task successfully. Steps in a task analysis should be stated in terms of observable behaviors with each step representing one "behavior." Once the step is complete, a visible change in the task or process occurs. Steps should be worded in the form of a verbal cue (e.g., "Pick up the file"). Task analysis may be useful in determining assistive technology and/or accommodations to support the completion of a respective task.

\section{Cross-References}

\author{
- Applied Behavioral Analysis \\ Dob Analysis \\ Job Site Training \\ - Supported Employment
}

\section{References and Readings}

Jonassen, D. H., Tessmer, M., \& Hannum, W. H. (1999). Task analysis methods for instructional design. Mahwah: Erlbaum. 